\title{
EU research funds to be diverted to fusion reactor
}

European nations hope to redirect more than $€ 1$ billion (US $\$ 1.25$ billion) earmarked for research grants to make up a budget shortfall at the experimental ITER fusion reactor, Nature has learned.

The proposal has alarmed scientists, who say that it will rob researchers of vital funds at a time when governments are planning to scale back domestic research budgets in response to the global economic downturn. "I think it's a small catastrophe in the present situation," says Helga Nowotny, president of the European Research Council, which funds research across Europe. "It's bad for European research."

Based in the south of France, the ITER reactor will one day fuse hydrogen isotopes to produce energy. When the project was agreed in 2006, it was expected to cost $€ 5$ billion to construct, but unofficial estimates now put ITER's price at about $€ 15$ billion (see Nature 465, 532-533; 2010).
As the largest contributor to the project, the European Union (EU) will have to pay $€ 7.2$ billion, far more than the $€ 2.7$ billion it had initially expected. The most pressing problem is a $€ 1$.4-billion gap in the construction budget for 2012-13.

A tentative agreement reached on 25 June by Europe's 27 member states would fill most of that shortfall using cash from the EU's Seventh Framework Programme (FP7) for research, the main sciencefunding mechanism in Europe for 2007-13. FP7 has an overall "Europe cannot afford not to go forward with the project." budget of $€ 50.5$ billion and still has about $€ 20$ billion unspent.

The European Commission, the EU's executive body, is expected to fight the proposal, arguing that drawing so heavily on FP7 funds would damage other research goals. But insiders say that it is likely that a compromise deal would still see tens or hundreds of millions of euros given to ITER. FP7 programmes that have already been selected will not suffer, says Achilleas Mitsos, who was the director-general for research at the European Commission from 2000 to 2005 and was a negotiator on the ITER project. But FP7 would have difficulty absorbing the entire $€ 1$.4-billion cost, which might come at the expense of new projects, he says.

Mitsos predicts that the EU will continue to fully support ITER, because failure would incur heavy political and financial costs. "Europe cannot afford not to go forward with the project," he says. ITER's council hopes to agree a final plan at its next meeting, scheduled for late July. With that in place, the first ITER experiments could begin in late 2019 .

Geoff Brumfiel

See go.nature.com/4KK24o for a longer version. 